\title{
Analysis on the Operation Modes and Strategies of China's Product Placement
}

\author{
Xu Meng \\ College of Economics and Management, Shangqiu Nomal University, Shangqiu, China

\section{Email address:} \\ xumeng-sq@126.com

\section{To cite this article:} \\ Xu Meng. Analysis on the Operation Modes and Strategies of China's Product Placement. Journal of Investment and Management. \\ Vol. 7, No. 3, 2018, pp. 81-85. doi: 10.11648/j.jim.20180703.12
}

Received: June 24, 2018; Accepted: July 6, 2018; Published: August 2, 2018

\begin{abstract}
When audiences are increasingly bored with mandatory advertisements for television programs, branding is vitally important to the company. Therefore, a new type of advertising named product placement has emerged. Compared with traditional advertisements, such advertisements can reduce the audience's resistance to advertisements. However, in real life, consumers are not satisfied with such kind of advertising due to various reasons.
\end{abstract}

Keywords: Product Placement, Operation Modes, Marketing Strategies

\section{Introduction}

\subsection{Background of This Study}

With the continuous development of new media technologies, traditional advertisements can no longer cater to the psychology of the majority of the audience. Therefore, the Product Placement has come to the front in this situation and is increasingly welcomed by advertisers. Product Placement is still not mature in various aspects due to the late appearance in China. And there are still many problems in the actual operation. Consumer's feedback is also less than satisfactory. The imperfection of legal system and regulatory measures has made these bad factors even worse, making Product Placement more unscrupulous and constantly challenge the sensitive and fragile nerves of the audience. Reasonable suggestions and countermeasures are proposed through the research on the status and existing problems of domestic Product Placement, hoping it is helpful for the healthy development of Product Placement in China.

Product Placement, also known as Product Placement Marketing, refers to the strategic integration of a product or brand and its representative visual notation or even service content into the content of a movie, television show, or television program, leaving the impression on the audience of the product and brand through a scenario representation and thereby achieving the purpose of marketing.[1] Immersive advertising and media carriers are mutually integrated to jointly construct a part of the audience's real life or ideal situation, and the goods or service information is conveyed to the audience in a non-advertising manner under the audience's unconscious modality. Due to its hidden characteristics, the product placement is also called an embedded advertisement or a soft advertisement. [2]

The sign of the product placement in China is a Chinese indoor sitcom directed by Feng Xiaogang in the 1990s. The Story of the Editorial Department not only promoted a large number of stars, but even made a property in the play called "Tianlong Mineral Water Pot" become so popular that once there was a company willing to buy out the right to use the trademark for 10 million yuan. It closed down due its bad management. However, this cannot evidence to deny the infinite opportunities that the product placement had brought to the Tianlong Mineral Water Pot. [3]

In recent years, Product Placement has become commonplace in China. The most successful case was the combination of Hunan TV's Super Girl and "Mengniu Milk". In this cooperation, the media has earned the money from the clients, and the clients have earned the money from the consumers by using the promotion of the product brand, which is a true "win-win" cooperation. In the movie Mobile Phone directed by Feng Xiaogang, the all-in-one Motorola mobile phone of the actors and the BMW car that Ge You drives wherever he goes have brought a lot of income to the crew. In No Thief in the World, 12 sponsors such as Hewlett-Packard, Canon, Nokia, BMW, China Mobile, and Great Wall 
Lubricants all got the opportunity for the brand to be shown in the film. Together with other brands' honorary sponsorship, it is said to have contributed 40 million for the crew. It can be said that Feng Xiaogang made a useful exploration of the development of Chinese embedded advertising. [4]

At present, the advertising saturation of the TV industry has reached a fairly high level. The effect of regular advertising has also been weakened by the viewer's remote control. The SARFT's time-limited advertisements have also made TV stations feel uncomfortable in this environment. Among them, the development of embedded advertising is the best choice for television media. Therefore, many TV stations have already tried to develop a product placement from a simple title and hanging corner to the embedded content. Hunan Satellite TV has achieved considerable success.

\subsection{The Significance of This Study}

Currently, ubiquitous and all-embracing advertisements generally use an interrupted mode to insert commercials between radio and television programs or between radio and television programs. Taking radio and television as an example, advertising is like a bolt, blocking the normal operation of the program flow. These ads are always trying to jump into our eyes with eye-catching ways, drilling into our ears from all directions to attract our attention. Interrupted advertisements often interrupt people's normal reading or appreciation activities. Under this model, advertisements become an unwelcome and uninvited guest and it is easy to arouse people's resentment. In real life, the audience often avoids advertisements by changing channels, jumping and shielding. The product placement is hidden in the carrier and integrated with the carrier. And at the same time, the advertising information is carefully coded with a non-advertising expression method in order to make the audience acquire the information of the goods and brands with an excellent information receiving environment in an unconscious state and thereby receive stimulation of advertising information. Since the audience accepts advertisements in a non-confrontational state, this advertising effect cannot be achieved by ordinary advertisements. When marketers market advertising to advertisers, the program's audience ratings are used as a basis for sales. However, the ratings of radio and television programs are not equal to the ratings of advertising. Advertising time often becomes the time for the audience to switch over and have a rest. Product Placement makes the implanted object an inseparable part and become an integral part of the images, props, scenes, characters, and plots of the media product. People can no longer separate advertising and media products through digital technology. If the audience wants to enjoy the show, they have to enjoy the ad at the same time. Embedded advertising also effectively avoids the price war among medias in the same city. In order to win an advertiser, there is often a price war for regular advertising among several radio stations in the same city. Because of the uniqueness of its programs and implantation methods, product placement has no comparability in price, which can effectively avoid price wars. [2] [5] [6]

\section{Main Operation Modes of Product Placement}

Looking at the operation modes of implanted advertising at home and abroad, it can be roughly divided into four types.

\subsection{Scene Placement}

Implantation of scenes refers to the appearance of a product or brand and its representative visual symbols as a part of a scene or a scene in which a movie story takes place. It is often exposed in the form of a shot or a close-up. It sometimes appears as a movie property. For example, in Dwelling Narrowness, the Nokia N95 used by Secretary Song, the Merchant Bank Card and the Sleepwalking Doll presented to the Haizao are all shot sufficiently for the viewer to notice the brand and model of the merchandise both in terms of duration and depth of field. [7]

\subsection{Dialogue Placement}

Dialogue Placement refers to the use of the audience's auditory system to subtly insert brand information into the film's language environment or character dialogues. For example, at the 2008 Spring Festival Gala, the host Dong Qing said, "We always hope the land yields good harvest and the people enjoy good health and good luck wherever we celebrate Spring Festival." And "The land yields good harvest and the people enjoy good health" is the slogan of China Life Insurance Company. [3]

\subsection{Plot Placement}

Plot Placement means that a certain brand or product becomes an organic part of the whole movie storyline. The brand or product not only appears in the film scene or the language environment, but also runs through the entire story. In Zeng Peng's earliest case of television drama Wang Gui and Anna, Wang Gui was prepared to buy an insurance for Anna in the early years. He told Anna several years later about the purchase of that insurance and said "I love you" which Anna has wanted for a lifetime to her. And those words pushed the story to the climax. This kind of episode implantation makes the brand's implantation become the transmission of characters in the play, which not only enriches the storyline, but also ensures that the implanted product will be remembered by the audience and the image will not be damaged. [7]

\subsection{Image Placement}

Image Placement refers to embedding a certain brand or product into a film according to the symbolic meaning of the brand, which becomes an external manifestation of the character's personality and connotation. At the same time, the brand's value and meaning are interpreted, the connotation of brand is enriched, the brand's uniqueness is enhanced, and thereby the brand's image is further improved. 


\section{The Advantages of China's Product Placement}

Compared with traditional advertising forms, the reason why Product Placement can develop so quickly in recent years is closely related to its series of advantageous features.

\subsection{Innovative}

China's traditional advertising content is pale and has always been in a state of low-level manufacturing. it can not only fail to attract viewers, but lead to resentment of the audience. For example, "Heng Yuan Xiang, Yang Yang Yang" is a way to focus on repeating three times. Although it is vulgar, it also allows people to remember Heng Yuan Xiang. The design of this brand advertisement is not innovative and aesthetically sensible, allowing the Chinese to change channels or do other things as soon as the advertising time comes. The display of overwhelming advertisements to the viewers has caused everyone to avoid being overly sensible. And product placements are presented to the audience in a way that the audience likes and feels, giving people a fresh feeling. Product Placement has changed the traditional broadcast mode of advertising. Through the constant introduction of new implantation methods, people feel fresh and thereby its dissemination effect is enhanced. The Product Placement can lead people to increase the intensity of thinking, make people feel more open and have deeper understanding of advertising, and thereby further enhance the audience's impression of the advertised product. [8]

\subsection{SARFT Issued the "Limiting Order" and Traditional Advertising Was Curbed}

For the case of implantable advertising, the example cited by a foreign writer is very representative. "If a character in a movie is drinking a bottle of unbranded beer, it's better to let him drink a bottle of Heineken." It is understandable that the characters in the movie drink Heineken in the movie. But if he takes a drink and puts down the bottle and says, "Heineken Heineken Beer is really good!" That's another story. It can be seen that the product advertisement sometimes is the full use of film and television resources and the placement of advertisements requires the director to make arrangements. Moreover, it should try not to reveal implicit advertisements. The flexible implantable method of Product Placement can combine more product information and programs that reflect people's lifestyle programs properly to give people a comprehensive understanding of the product's characteristics. Moreover, the natural integration effects of the new forms of implantable advertising make people more receptive and the insertion of advertising in entertainment programs can enhance people's interest on the brand and have strong penetration. [9]

\subsection{Strong Brand Penetration}

From the perspective of consumer behavior theory, the Product Placement will have an impact on the consumer's consumer behavior. In the media, such as television and movie, the star will play a demonstration role for the consumer through the interpretation of the product. Through this model of product placement, the audience has gained rich brand association and brand preference based on the deepening of brand influence, and then companies finally won wide recognition and brand value enhancement. This subtle influence is exactly the sponsor's dream. Therefore, through the reasonable use of the implantable advertisement, it not only helps to increase the target audience's recognition and favorability of the recommended brand, but also helps to enhance the brand image and market influence and expand the brand market. [10]

\section{The Existing Problems of China's Product Placement}

In recent years, embedded advertising has gradually become known to the people and gradually become an important means for advertisers and producers to make profits. Facing the temptation of huge economic interests, advertisers and producers have even blindly implant advertisements without caring about whether they are related to the content of the work. For a time, there seems to be no trace of embedded advertising in various film and television works. Today, we are free to turn on the TV and we are likely to see naked advertisements without technical content in programs such as variety shows, draft shows, dialogues and interviews. The consequence of this is that consumers are enduring the hardship brought about by the blunt advertising while advertisers and operators are happily savoring the cake of interest. At present, the following problems are the main ones in the production process of the Product Placement.

\subsection{The Frequency of Advertisements Is too High, with Various Types}

Taking the Let us watch star shower together which is considered as the most criticized TV drama in history as an example, there are about 25 different brands of advertisements planted in this TV series, covering automobiles, apparel, shampoo, sports shoes, food, beverages, banks, computers, and pharmaceuticals. On average, the adverts will be broadcast every minute. Therefore, it gained the nickname "thunderstorms" and the reputation of "the longest commercial in history."

\subsection{The Lack of Artistic Implanting Techniques and Forced Placement}

The Product Placement must be consistent with the plot scenario of the program. However, some producers and advertisers who pursue effectiveness insert advertisements that are not related to the plot of the program forcibly or even segments that are very different from the plot, making the production blunt and the brand become confused. The invaders will often cause visual discomfort to the audience, interfere with their viewing effects and even affect the movie's 
reputation and value. The advertisement of certain brand of shampoo in Let us watch star shower together is out of the story, show the features of the product too straightforward and its implant is very abrupt. It is surely a direct advertisement in TV series. [11]

\subsection{The Effect of Advertising Is Not Obvious}

In the movie, the product placement is attached, and it is subordinate to the needs of the development of the movie plot. It is the plot and role of the movie that attracts viewers' attention. Therefore, viewers tend to ignore the existence of product placement in the movie. The advertising investment pursues the advertising effect. Only when the effect is good, the advertiser will pay for the advertisement. For those brands with relatively low visibility, it is still a difficult matter to rely on a movie to make it famous. After all, as an affiliated product placement, it can not replace the status of the story. The assessment of effectiveness in the advertising field is almost blank, and it can only estimate its investment and return. This also severely restricts the scale effect of the film-imposed advertising market. [12]

\subsection{Product Placement Violates China's Laws}

Article 13 of China's Advertising Law stipulates that advertising should be identifiable and enable consumers to identify it as advertising. Mass media may not publish advertisements in the form of news reports. Advertisements published through the mass media should be marked and distinguished from other non-advertising information and should not lead to misunderstandings among consumers. Implantable advertising clearly does not meet the above requirements. Audiences buying tickets to watch movies is a kind of payment behavior. Placing too many advertisements into movies and even making an advertising campaign obviously violate the principle of equal exchange in market transactions. In the event of an implantable film and television advertising business, due to the lack of professional advertising companies, the advertisement agency system and advertising archives system of the advertising certification system for advertising business approval systems cannot be effectively implemented, which makes the legality of advertisements scientific and lose protection. Once legal disputes arise, the legal responsibilities of advertisers and producers are indistinguishable. [13]

This series of operational problems has caused the audience to resent and be dissatisfied with Product Placement, which constitutes a bottleneck that restricts the development of Product Placement and affects its healthy and long-term development in China. China's Product Placement urgently need to be changed from this kind of extensive, low-level development that is unprincipled, unconstrained and unordered.

\section{Countermeasures and Suggestions}

\subsection{Improve the Legal System}

In the face of the explosive growth of implanted advertising,
China has a lack of legislation, related systems and other aspects, including the "Advertising Law" which does not cover this new form of advertising, resulting in that the relevant functional departments can not have an accurate assessment about the embedded advertising of its legitimacy. This makes product placement outside the scope of existing laws and regulations. It is suggested to combine the characteristics of the product placement to clarify how to manage product placements by modifying the Advertising Law or formulating regulations separately. For example, define the scope and form of the implantable advertising, and clearly define the using scope of Product Placement, including programs can be implanted, programs that can not be placed, as well as the time and quantity of implanted advertising.

\subsection{Product Placement Must Conform to the TV Series}

Analyzing the advertiser's target consumers does not intersect with the target audience of the movie or TV show or program. This is a problem that should be prioritized when using embedded advertising. It is obviously unsuitable to implant a product in a TV drama targeting a family woman. The separation of the target audience will cause the advertisement to be invalid or inefficient. In No Theif in the World, it showed BMW's flexibility and powerful braking system that made people add confidence to BMW's performance when Andy Lau steered BMW smoothly to avoid the oncoming large trucks. This successful and product-targeted advertisement is sufficient to show that the product placement is consistent with the target content.[14]

\subsection{Establish a Sound Assessment Mechanism}

At present, the operation of implanted advertising has not yet had a complete set of mechanisms involving research, planning, argumentation, and effect evaluation. There is no accurate assessment of implanted advertising. The biggest problem that this brings is the uncertainty of quotation. The effectiveness of the placement is ultimately determined by the length of exposure, hearing, and plot. From a practical point of view, for the same program, the different methods of advertising implantation will make the effects very different; but the assessment of such soft indicators is more difficult. The evaluation of the effectiveness of the implanted advertising is an urgent problem to be solved. [15]

\subsection{Implement Strong Supervision}

To make implantable advertising develop in a long-term way, a strong regulatory system must be implemented and it cannot be left to develop alone. The state should revise and supplement the current advertising law according to the status quo of the implanted advertisements and the problems that have already emerged, and clarify the various implementation systems of the implanted advertisements, such as business approval, advertisement review, advertising agency, advertising fees and so on. We will revise and improve the advertising law as soon as possible, establish a legal supervision system for implantable advertising, give legal 
status to it, formulate standardized standards, and strengthen government oversight on it, which is the current urgency of Product Placement in China. The immediate imperative of advertising is also the fundamental solution to effectively solve the problem of film-based product placement.

\section{Conclusion}

How to place an orderly and healthy development on the track of implantable advertising depends on the relevant laws and regulations of the country. More importantly, in the absence of the constraints of the rules and regulations, the development of implanted advertising depends on commercial ethics. Implantable advertising has the advantage that invisible advertising is incomparable. In response to the requirements of the development of the times, as long as the degree of product placement is controlled and the balance between quality and quantity is controlled, the audience can accept the advertising content with a pleasant mood.

\section{References}

[1] Xu Tan. Shi Changzheng (2012). Rational Development of Product Placement. Modern advertising (4): 74.

[2] Zhang Benyi (2016). The dissemination effect of product placement in the new communication environment. Young reporter (8), 86-87.

[3] Zhang Bin (2008). On the Application Strategy of Product Placement. Modern audiovisual, 54 (3): 54.

[4] Li Shenglong (2011). Discussion on Chinese Film Product Placement. Journal of Guizhou University for Nationalities (5): 147.
[5] Wang Kai, Liu Xiao, Yu Yi Xin, Guo Guangjun (2017). Analysis of product placement in large-scale TV activities. Contemporary TV (10), 69-70.

[6] Yang Yan Jun (2016). Analysis of the development of implantable advertising in network homemade drama. Publishing wide-angle (23), 69-71.

[7] Wan Jun (2012). Problems and Countermeasures of Operational Models of Chinese Cinematic Implantable Advertising. Journal of Suzhou College of Education, 29(3):12-13.

[8] Rong Yi (2012). An analysis on the Marketing Strategy of Product Placement. Value Engineering.

[9] Zhang Liping et al (2012). Establish a New Paradigm for Chinese-style Product Placement. Journal of Social Science of Jiamusi University, 30(3): 169.

[10] Ma Rugao and Wang Yan (2012). The Impact of Implantable Advertising on Brand Evaluation. Expert Forum, (265): 19.

[11] Li Ning, Lei Tingting (2012). Analysis on the Problems and Countermeasures of Product Placement in China. Journal of Tianjin Vocational College, 14 (4): 81-82.

[12] Yu Haijun (2011). Analysis on Advantages and Inadequacies of Chinese Film Product Placement. Journal of Jilin Provincial Institute of Education, 27(11): 49

[13] Zhang Juanli (2016). Analysis of the legal regulation of product placement. China TV (10), 105-108.

[14] Xu Lili (2017). Research on narrative strategies of brand culture embedding in movie situations. Contemporary films (8), 183-186.

[15] Xu Yongshun (2017). Deep hierarchical expression -- Analysis of the art of implantable advertising microfilm. Film review (20), 87-89. 